\title{
PHYSICAL AND ANALYTICAL MODELING OF RHYTHMIC KARST SPRINGS
}

\author{
Xianxuan Xiao ${ }^{1, c}$ and Qiang Zhang ${ }^{1}$
}

\begin{abstract}
Rhythmic Karst Springs (RKSs) are rare geologic features that rhythmically outflow water. A mechanical model for the rhythmic flow with rhythmic spill-over configuration was constructed in this work. The evolution of the RKS was revealed by using geological process analysis. The analytical model can directly explain the existence of RKSs in soluble rock regions and their formation mechanism in nature. Visual observations and flow measurements were performed using a laboratory physical model of RKS. The physical model components included a soluble rock simulation area, karst pipes, cave-reservoir, karst depression terrain, water tank, rhythmic spring, and the outflow measurement system. Groups of tests were carried out to recreate the process of RKS functioning and to confirm the rhythmic cycle duration and the threshold of replenishment intensity. This research helped to interpret the behavior of rhythmic springs using the recharge and evacuation of the subsurface cave-reservoir by means of fluid mechanics and groundwater hydraulics theories.
\end{abstract}

\section{INTRODUCTION}

Rhythmic Karst Springs (RKSs) have intrigued scientists for centuries (Cvijić, 1896; Marković, 1963; Gavrilović, 1967; Petrović, 1981; Bonacci and Bojanić 1991; Mirković and Miljković, 2006; Kolda et al., 2019), and they are named in different ways in the previous works, such as ebb and flow springs, potajnice, and rhythmic springs (Bonacci and Bojanić, 1991). They are regarded as an extremely special kind of spring, which are rare but are distributed all over the world. According to past studies, rhythmic springs (RSs) appear exclusively in areas consisting of soluble rocks. Soluble rocks are those that dissolve in water, leaving almost no residue. Atkinson (1986) described the formation of rhythmic springs. The dissolution of rocks tends to widen the fissures by weathering without blocking them at the same time, allowing groundwater to penetrate and expanding them further.

The RKSs represent an interesting phenomenon that occurs relatively rarely (Bonacci and Bojanić, 1991). The flow of most RKSs is normally not plenty, and it possibly has no critical influence on water source evaluation or regional hydrogeological calculation. An ebb and flow spring, Laywell Spring, is located in a famous landmark of Brixham, Devon, UK (Oliver, 1693). A scheme of interacting reservoirs and syphons was proposed to explain the workings of Laywell Spring (Atwell, 1732). The Laywell occurs at the junction of Middle Devonian limestones and mudstones about 36 meters above mean sea level. It works at 9 to 20 cycles per hour and it is interrupted by periods of varying length or at irregular times. Laywell was once used for public water supply but its use ceased around 1840 by the local load works or through mining and quarrying of limestones (Mather, 2013). RKSs play an important role in nature tourism by developing the tourism industry and enhancing the local economic effect in karst regions. There are about ten rhythmic springs in the USA and six rhythmic springs in France (Bögli, 1960). Gavrilović and Gavrilović (1985) refer to the appearance of about 20 rhythmic karst springs in the karst region of former Yugoslavia. These authors indicated that it is impossible to judge whether the outflows of these springs are real rhythmic springs or not. They also stated that there are more than 33 rhythmic springs in the world, apart from those in the former Yugoslavia: three in Hungary, seven in France, at least eight in China, two each in Bulgaria, Romania, Switzerland, England, and Belgium, and only one each in the former Czechoslovakia, Germany, USA, the Soviet Union, and Israel (Bonacci and Bojanić. 1991).

One-third of the national land area is covered by soluble rocks in China, about 0.91 million square kilometers. Especially in south China, there are various kinds of soluble rocks such as limestone, dolomites, salt rock, and gypsum that are distributed in the Middle Triassic system (mainly dolomites), Lower Permian system (limestone), Ordovician system (mainly limestone), and Lower Sinian system (mainly dolomites). The high karstification terrains typically have strong tectonic movement, deep-cutting valleys, relatively pure soluble rocks, and abundant rains, which generate karstification phenomenon with dissolution cracks, karst caves, stalactites and stalagmites, karst dissolution pipeline, and even subsurface hidden rivers. Therefore, some rhythmic springs must undoubtedly exist. So far, eight rhythmic springs have been revealed in China. Other ones are only reported by mass media or newspapers in the tourism industry.

An interpretation for rhythmic springs functioning by siphon systems was proposed (Katzer 1909; Lazarević, 1990; 2000). Bonacci (1987) presented the schematics of the functioning mode of RKS. His work stated that all the water in the cave-reservoir will outflow suddenly once the water level reaches a siphon water level. When the water level is much higher than the siphon water level, the total flow of the water recharge from underground channel (karst pipes) or

${ }^{1}$ State Key Laboratory of Geohazard Prevention and Geoenvironment Protection, Chengdu University of Technology, Chengdu 610059, Sichuan, China.

c Corresponding author: xiaoxianxuan2012@cdut.edu.cn; ORCID: 0000-0003-1366-620X 
cracks exceeds the maximum capacity of the siphon. Then, the outflows of the spring will maintain the stream all the time. Bögli (1980) explained the possibility of the RKS functioning in four situations, which includes the length of the rhythmic period, the air action, water recharge capacity from the surrounding crack and karst pipe of the basin reservoir. These aspects result in variation of water level in the basin for rhythmic action.

Researchers prefer the term rhythmic springs to the term intermittent springs for emphasizing the siphon action that induces the effect of rhythmic phenomenon in the outflow hydrographs. A classification of rhythmic springs was proposed as follows (Gavrilović, 1967): (1) permanent rhythmic springs; (2) seasonal rhythmic springs; (3) rhythmic springs occurring during the rainy season or the dry season; (4) sudden rhythmic springs. This last kind of spring probably has a great number of groundwater reservoirs either connected in series or in parallel, which was found in the former Yugoslavia. Such a shape was defined as the Kojin Spring hydrograph (Bonacci and Bojanić, 1991).

Previous studies on rhythmic springs mostly focus on the qualitative analyses, siphon process description (Katzer, 1909; Casteleyn, 1977; Bonacci, 1987), and classification of the rhythmic springs (Gavrilović. 1967). However, some aspects involving quantitative evaluation such as mathematical models and physical simulation models of rhythmic springs remain extremely scarce. It is important to indicate the whole-formation geological process and to reveal the genetic mechanism and its evolution characteristics. In this work, a physical model was proposed for the simulation of a rhythmic spring. The main objectives of this study were to evaluate how these cavities, dissolution pipeline geometries, and several chambers work together and function as a rhythmic spring, and to interpret the hydraulic and morphological aspects of the rhythmic springs, as well as how they evolve over time by groups of tests and analysis.

\section{MATERIALS AND METHODS}

The goal of this research is to reveal the main variables/factors involved in the RKS system and their effects on the RKS. Based on field work of previous studies, it is worthwhile to investigate and reveal the characteristics of RKS, which can help to better understand its mechanism. The approaches include analytical modeling, physical model construction, and tests for the quantitative analysis of RKS.

\section{RHYTHMIC SPRINGS MEASUREMENT IN THE FIELD}

Until now, real-time monitoring and measurements of rhythmic springs are rare. Table 1 gives the details for six rhythmic springs in China and one in Serbia, including the discharge of the rhythmic springs and the periods. The testing time of the rhythmic springs in China was around the 1970s. The Homoljska Potajnica spring in Serbia was measured in July 2012.

Homoljska Potajnica is one of the three known rhythmic springs in Serbia. It is located in eastern Serbia, on the southern slopes of Mt. Homoljske Planine and in the Valja Mori river valley which belongs to the Mlava river basin (Igračev, 2014). Igračev (2014) took two precise measurements of the Homoljska Potajnica spring showed similar shape, durations, and water discharges (Fig. 1). The analysis of the water hydrograph shows that it increased linearly after the discharge occurred and reached its maximum value $\left(2.8 \mathrm{dm}^{3} \mathrm{~s}^{-1}\right)$, and decreased irregularly after the peak in an instant. Two consecutive discharges are almost the same. The difference between them can be a result of limitations of the measurement process itself by the continuous monitoring under relatively dark conditions due to the weather (Igračev, 2014). This example confirms the periodic eruption and the siphon effect which impacted on the discharge of Homoljska Potajnica. It would be interesting to perform further quantitative research by physical model experiments and analytical modeling.

\section{EXPERIMENTAL SET UP}

\section{Geological Conceptual Model for Physical Modeling}

The generation process and geological evolution of RKS in karst terrains are illustrated in Fig. 2. Under the influence of tectonic action, shear joints are commonly developed and exist in the soluble rocks in these regions. A hole was

Table 1. Some of the measured rhythmic springs in karst regions. For the rhythmic springs in China, the testing time of discharge and periods was around the 1970 s.

\begin{tabular}{ccccc}
\hline Name of RKS & Country / Region & Discharge (dm $\mathbf{3} / \mathbf{s})$ & Period (min) & Testing time \\
\hline No. 1 Hongbanqiao (HBQ-1) & Guizhou, China & $88.55 \sim 0.45$ & $33 \sim 41$ & Before 1979 \\
No. 2 Hongbanqiao (HBQ-2) & Guizhou, China & $28.5 \sim 0.24$ & $33 \sim 41$ & Before 1979 \\
Baihua (BH) & Guizhou, China & $3.5 \sim 1.5$ & $10 \sim 15$ & Before 1979 \\
Cichong (CC) & Guizhou, China & $108.86 \sim 43.75$ & 29 & Before 1979 \\
Xianglongdong (XLD) & Guizhou, China & $139 \sim 1.0$ & 20 & Before 1979 \\
Huangnidong (HND) & Chongqing, China & $500 \sim 50$ & 81 & $1969 \sim 1970$ \\
Homoljska Potajnica (HP) & Serbia & $2.8 \sim 0.016$ & & July 2012 \\
\hline
\end{tabular}




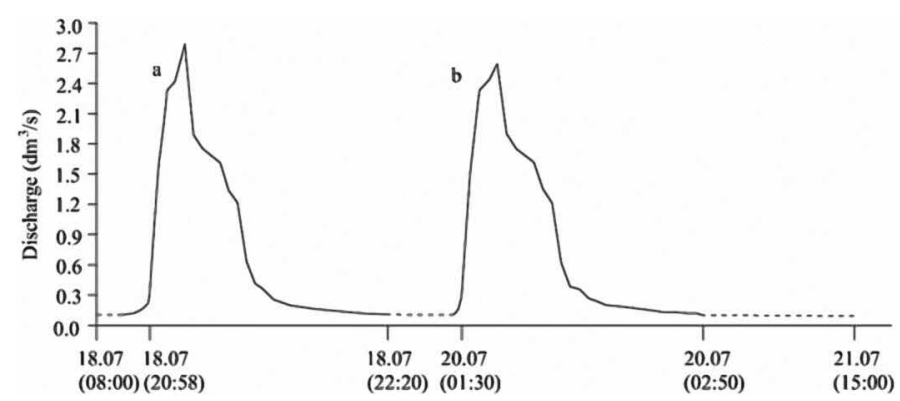

Figure. 1 Discharge hydrography of Homoljska Potajnica on July 18th (a) and 20th (b) in 2012 by field measurement. Two precise measurements showed similar results. Although the final model of Homoljska Potajnica activity cannot be determined, it can be assumed that in extremely arid period, as was the summer 2012, Potajnica was probably in a relatively stable status. The main features (duration of water eruptions, discharged water amount) are almost equal for the two cycles, while the stopping time is related to the time delay from the arid climate (Igračev, 2014).
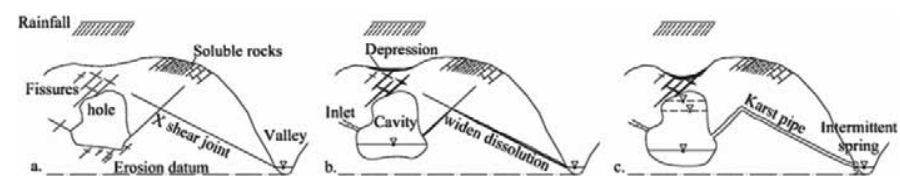

Figure. 2 The geological background of a rhythmic karst spring conformation. (a) cave prototype formation stage, fissures around a dissolved hole in the soluble rocks; (b) the hole receives replenishment and expands as the cavity fills with water. The surface evolves into a depression by rainfall, the karst pipe and fissures offer channels for the streams; (c) the major fissure evolves into a karst pipe by continuous widening dissolution, and the rhythmic spring is formed.

water. The total flow of the spring reached the maximum value karst pipe was washed away and it was fully filled with

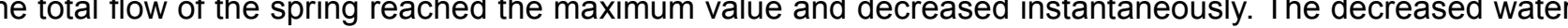
level supplied a lower water head pressure with siphon effect, resulting in the attenuation of total flow of the spring. After the water level decreased to the connection point of the cavity and the karst pipe, air passed through the karst pipe and the siphon disappeared. Thus, the flow at the outlet was equal to zero. The continuous flow into the cavity without discharge caused the water level to increase again, and RKS to run periodically (Fig. 2c).

\section{The Laboratory Physical Model}

The goal of using a laboratory model of rhythmic karst spring is to simulate the evolution of the processes, to represent the rhythmic spring function, and to define the cycle duration. The laboratory model of rhythmic karst spring contains three primary components: 1) a physical subsurface karst stratum that contains a single large cavity and a small diameter, inverted $\mathrm{U}$-shaped pipe that is open to the atmosphere at the lower end and an air layer at the bend of the U; 2) a water supply system consisting of a constant head tank, a low power water pump, and a water tank at the bottom; 3) a flow measurement system, which includes a water table ruler and triangular weir plate. The laboratory model is made of acrylic plastic and the water tank is made of $15 \mathrm{~mm}$ thick PVC tubing. A square metal rod was used to stiffen the physical model and increase its strength. The conduit was a cylinder and the diameter was selected to be large enough so that the effects of surface tension of fluid can be neglected. The diameter of the reservoir was chosen to be large relative to the diameter of the $U$-shaped conduit and the physical model, as is likely the case in the natural outlet of an RKS (Fig. 3).

Flow flux is the main parameter that was measured in all the tests. The triangular weir was used to monitor the real time flux of water, by measuring the water relative elevation with the water table rule. The initial elevation relative to the weir is $H_{0}, H_{0}=9.0 \mathrm{~cm}$. Whenever the water flows through the triangular weir, the elevation of the water table can be measured at each moment and is noted as $H_{1}$. Thus, the flow of water can be calculated as $Q 5 m h^{5 / 2}$, where $h=H_{1}-$ $H_{0} ; m$ is the flow coefficient, $Q$ is the flow;

$$
m=1354+\frac{4}{h}+\left(140+\frac{200}{\sqrt{D}}\right)\left({ }_{B}^{h}-0.09\right)^{2}
$$

where $D$ is the distance from the underside of the weir box to the lowest point of the weir opening, $D=0.1 \sim 0.75$ meters; $B$ is the width of weir box, $B=0.1 \sim 0.5$ meters. 

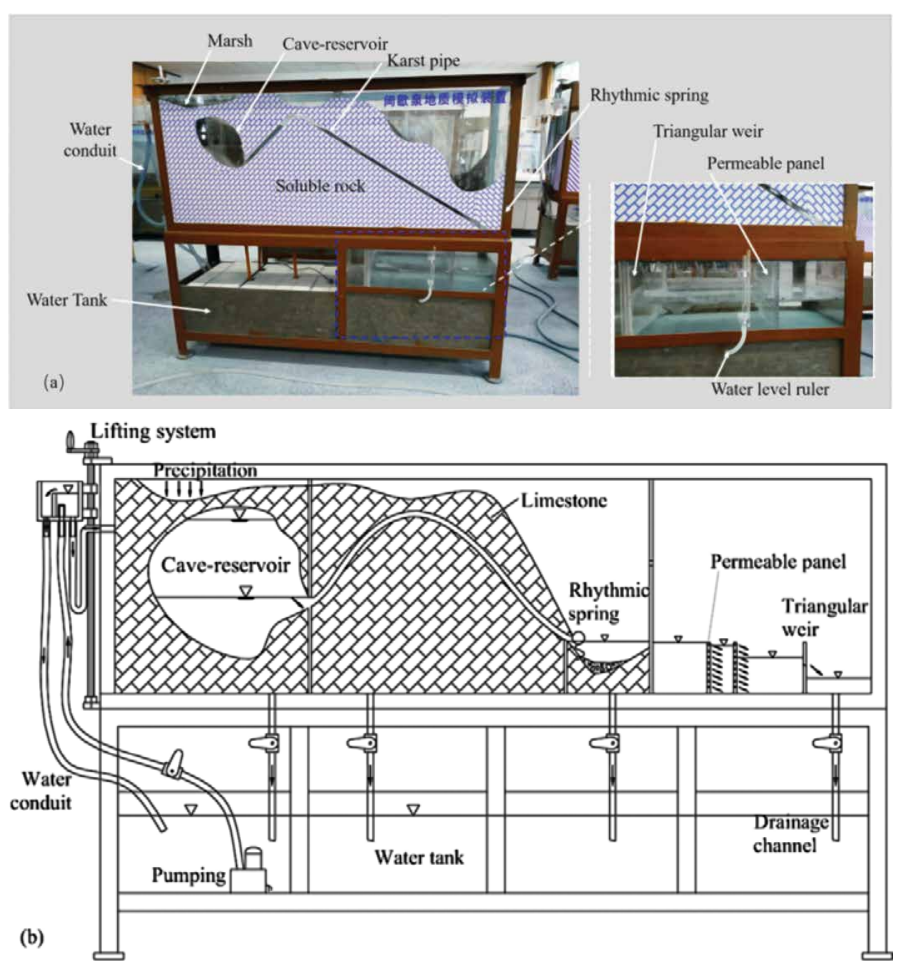

Figure 3. The physical laboratory model of the RS: (a) photo of the physical model of the RS, which includes a cavity reservoir in the soluble rocks; a karst pipe in the soluble rock that developed from a group of shear joints superficial transformation, RS; soil was on the top of the cave-reservoir, the water supply system and the triangle weir flow measurement system and (b) the schematic of the physical laboratory model and water circulation of the simulated specific karst system.
For each experimental run, water was first filled up to two-thirds volume in the tank ensure enough water in the process of each test. The water pump introduces the water from the tank to one side of the stable water flow box through the plastic water hose. The remaining water flows to another side of the stable water flow box and downwards to the water tank by another plastic hose as the water in the stable water flow box is fully filled. Then, most of the water in the stable flow box flows to the gaping depression that is set on the top of the physical model. Subsequently, the water infiltrates into the cavity through the simulated vertical fissures and the water table in the cavity rises up. The water level in the karst pipe remains the same as the cavity because of their connectivity. Water in the cavity cannot flow out from the karst pipe until the water level is higher than the lower critical point of the karst pipe turning. Once water flows out, the water level in the cave-reservoir is recorded as $H_{1}$. The Siphon effect appears when the water level in the cavity exceeds the upper critical point. Once the siphon effect is generated, the water level in the cave-reservoir is recorded as $\mathrm{H}_{2}$. Then, the water level declines and a stream of water flows from the outlet of the spring; the flow attenuates gradually and is equal to zero instantaneously; the cavity receives recharge from the top and the water level increases again; and the siphon replays again. The triangular weir system allows perfect flow measurement for the entire test process.

\section{Testing Approach and the Tests Setup}

The replenishment and the volume of the cave-reservoir have an important effect on the rate of water level rise in the cave-reservoir as well as the cycle duration. However, the relationship between the replenishment of the cave-reservoir and the cycle duration is still unknown, such as the hydraulic boundaries of the RKS within which the hydrograph appears different and the maximum and minimum flow of the RKS. In this regard, it would be useful to reveal the influencing factors of the flow and the cycle duration for water management, sustainable development and utilization in karst terrain.

Eight tests were carried out by using the physical model, including different water replenishment values of the cave-reservoir and different volumes of the cave-reservoir. The device structure and the initial experimental conditions are given in Table 2 .

Table 2 There are two types of cave-reservoirs which are distinguished by size (A represents one-third of the maximum size of the cave-reservoir, A + B represents the maximum size of the cave-reservoir). The elevation of the outlet of the RS equals 0 . Scheduled number of cycles in $A+B$ is less than $A$, enough for the cycle duration comparison.

\begin{tabular}{ccc}
\hline Test Number & Cave-Reservoir Type & Scheduled Number of Cycles \\
\hline 1 & A & 10 \\
2 & A & 10 \\
3 & A & 12 \\
4 & A & 11 \\
5 & A & 10 \\
6 & A + B & 2 \\
7 & A & 12 \\
8 & A + B & 2 \\
\hline
\end{tabular}

Notes:

Elevation of the key points in the analog karst system: $h_{1}=77 \mathrm{~cm}, h_{2}=71 \mathrm{~cm}, h_{3}=37.6 \mathrm{~cm}$, and $h_{4}=0 \mathrm{~cm}$.

Cross-sectional area of the pipe $=3.142 \mathrm{~cm}^{2}$.

Maximum height of reservoir $=35 \mathrm{~cm}$. Maximum width of reservoir $=42 \mathrm{~cm}$. 
Each of these tests was conducted as follows. (1) Check the instrument, make sure the water valves are normal and the analog karst pipe is unobstructed; (2) the water in the tank can be introduced by the pump after power on; the water replenishment is controlled by the water table controller on the left side of the model by rotating the lifting system in clockwise or counterclockwise direction, and the elevation of the water table controller represents the intensity of water replenishment; (3) measure the initial weir elevation at the downward side of the model, once the outlet of the RS is flowing; measure the water head on weir one time per second until the water head equals the initial weir elevation. In the process of testing, observation, photographs, and recorded data are needed.

From Test 1 to Test 4, the volume of the cave-reservoir was constant and the water replenishment increased step by step to obtain the changes in maximum flow, minimum flow, and the cycle duration. Test 5 and Test 6 , and Test 7 and Test 8 were considered as two groups. The water replenishment was constant but the volume of the cave-reservoir was different in each group.

\section{Analyses of Hydrological Condition}

The siphon effect is the main factor that induces RKS. The fluid movement from the cave reservoir to the outlet follows the law of Newton inner friction, momentum and energy conservation law. The Bernoulli energy conservation equation was used to describe the fluid movement

$$
z_{1}+\frac{P_{1}}{\gamma}+\frac{a V_{1}^{2}}{2 g}=Z_{2}+\frac{P_{2}}{\gamma}+\frac{a V_{2}^{2}}{2 g}+h_{w}
$$

where $z_{1}$ is the elevation head; $\frac{P}{\gamma}$ is the pressure head; $\frac{\alpha V^{2}}{2 g}$ is the velocity head; $V$ is the water flow velocity in the karst pipe of the physical model; $h_{w}$ is the head loss, which represents the energy lost during the water stream; $\alpha$ is the kinetic energy correction factor, for running water, $\alpha \approx 1 ; z+\frac{P}{\gamma}$ is the piezometric water level; $\gamma=\rho g$ is the test weight of water, $\rho$ is the density of water, and $\gamma$ is the acceleration of gravity.

Applying the following assumptions: (1) the water in the experiments is considered as an ideal and incompressible fluid; (2) the flow is a steady flow; (3) gravity is the only mass force in the experiments and (4) particles flow along a specific streamline $h_{w}$ is equal to zero to Equation (1) resulted in

$$
z+\frac{P}{\gamma}+\frac{\alpha V^{2}}{2 g}=C
$$

where $C$ is a constant that represents the total mechanical energy of the fluid.

The water flow velocity in the karst pipe was calculated by

$$
\left\{\begin{array}{c}
Q=V_{1} A_{21}=V_{2} A_{22}, \\
A 2=\frac{\pi d^{2}}{4}
\end{array}\right.
$$

where $Q$ is the flow in the karst pipe; $A_{21}, A_{22}$ represent upstream and downstream arbitrary cross-sectional areas of the karst pipe, respectively; and $d$ is the diameter of the karst pipe.

\section{RESULTS}

This work investigated the RKSs functioning and process by analytical modeling and a group of tests based on the physical model. The water flow velocity of the RKS, the flow of the RKS, the negative pressure at the siphon water level, and the cycle duration were derived. The results of the model tests include two main categories of rhythmic phenomena (rhythmic flow and cut-off, rhythmic flow and uncut) and the impact of variable volume of the cave-reservior on the hydrographs.

\section{Analytical Model}

The karst pipe is smooth and even, and its diameter is constant. The water flow velocity at the RKS outlet and the negative pressure at the siphon level can be calculated.

It was postulated that the water level in the cave-reservoir $h_{1}$ is unchanged temporarily (Fig. 4), considering the outlet of rhythmic spring as the datum plane $\left(h_{4}=0\right)$, from $h_{1}$ to $h_{1}$. Then, the Bernoulli equation was established as:

$$
z_{1}+\frac{P_{1}}{\gamma}+\frac{V_{1}^{2}}{2 g}=z_{4}+\frac{P_{4}}{\gamma}+\frac{V_{4}^{2}}{2 g},
$$

where $V_{1} \approx 0$, compared to $V_{4} ; p_{1}=p_{4}=p_{a}, p_{a}$ is the atmosphere pressure. Equation (4) can be simplified to $z_{1}=z_{4}+\frac{v_{4}^{2}}{2 g} ; z_{1}=h_{1}, z_{4}=h_{4}=0$. Hence, the water flow velocity at the RKS outlet can be calculated as:

$$
V_{4}=\sqrt{2 h g_{1}}
$$




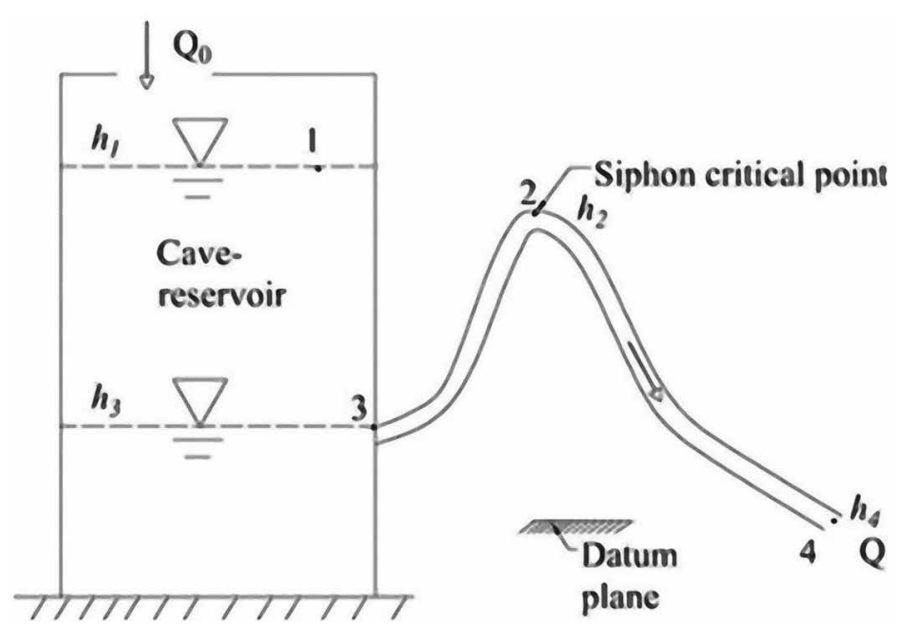

Figure 4 Simplified hydrograph of rhythmic spring action.
The flow of the RKS can be calculated using the following formula:

$$
Q=\frac{\pi d^{2}}{4} \sqrt{2 h g_{1}},
$$

Equation (5) indicates the relationship between the water flow velocity at the RKS outlet and the water level in the cave-reservoir. Before the siphon action, the water level in the cave-reservoir rises up due to the water infiltrating from the depression, which can accumulate water during precipitation or by the recharge from karst pipe streams. If the water level in the cave-reservoir reaches the crucial water level $h_{1}$, the siphon effect yields and the water level in cave-reservoir declines below the crucial water level $h_{1}$. $A$ reduced water level in the cave-reservoir induces the decrease in water flow velocity at the RKS outlet.

The negative pressure at the siphon level is $p_{\mathrm{r}}=p_{2}-$ $p_{a}$. From $h_{1}$ to $h_{2}$, the Bernoulli equation can be expressed as:

$$
z_{1}+\frac{P_{1}}{\gamma}+\frac{V_{1}^{2}}{2 g}=z_{2}+\frac{P_{2}}{\gamma}+\frac{V_{2}^{2}}{2 g}
$$

where $V_{1} \approx 0$, compared to $V_{4} ; p_{1}=p_{a}$. According to Equation (3), $\bar{V}_{2} A_{22}=\bar{V}_{4} A_{24}$ can be obtained by using continuity fluid equation from $h_{2}$ to $h_{4}$. Since $A_{22} A_{24}, \bar{V}_{2} \bar{V}_{4}$. As the water flow velocity at the RKS outlet cross-section is evenly distributed, $\bar{V}_{4}=\bar{V}_{4}$. Then, Equation (7) can be simplified to $\frac{P_{2}}{\gamma}=\left(z_{1}-z_{2}\right)+\frac{P_{1}}{\gamma}-\frac{V_{2}{ }^{2}}{2 g}$ where $p_{1}=p_{a}$. Hence, the negative pressure at the siphon level position is derived as follows:

$$
P_{r}=\gamma\left[\left(h_{1}-h_{2}-\frac{\left(\sqrt{2 h g_{1}}\right)^{2}}{2 g}\right]=-p g h_{2},\right.
$$

Equation (8) indicates that the negative pressure at the siphon level (siphon critical point) depends on the elevation from siphon crucial point to the outlet of RKS $\left(h_{2}\right)$. Here, $h_{2}$ is a constant parameter which depends on the structure of the designed device or the natural formation karst system.

According to Equation (5), the water flow velocity at the RKS outlet $V_{4}$ depends on the water level of the cave-reservoir $h_{1}$. In fact, the water level in the cave-reservoir changes all the time, which induces the change in water flow velocity at the RKS outlet $V_{4}$. On the other hand, the change in $V_{4}$ has an influence on the water level in the cave-reservoir. The decrease in $V_{4}$ leads to reduction of the flow of RKS. It is interesting to understand how the water level changes with time in the cave-reservoir. Suppose that the replenishment $Q_{0}$ is a constant parameter (the recharge from precipitation

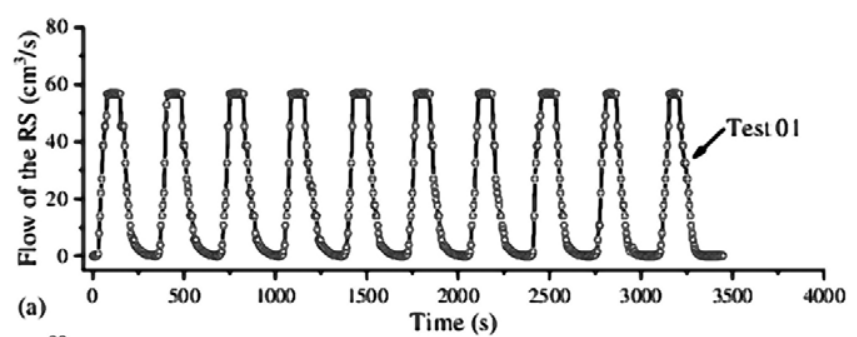
or the karst pipe, soluble cracks), the cave-reservoir is a regular cylinder, and its bottom area is $A_{1}$, the karst pipe is even and its cross-sectional area is $A_{2}$, and both $A_{1}$ and $A_{2}$ are constant. The following points explain the boundary conditions of the water-level declining with time:

1. First, $h_{1}$ increased linearly due to the recharge of the stable infiltrate flow $Q_{0}$, because the bottom area of the cylinder was fixed, and there was no flow at the outlet of RKS.

2. The siphon effect started as soon as the water level rose to the maximum value of $h_{1}$ (Fig. 6, point 1). Subsequently, both the water flow velocity at the RKS outlet $V_{4}$ and the flow of RKS $Q$ reached the maximum value, and $Q>Q_{0}$.

3. $Q>Q_{0}$ induced the decrease in water level in the cave-reservoir. Subsequently, the lower water level in the cave-reservoir caused the reduction of both the water flow velocity at the outlet and the flow of RKS. The interaction of the water level and the flow of RKS caused the siphon effect to disappear and the break of water flow. With the 

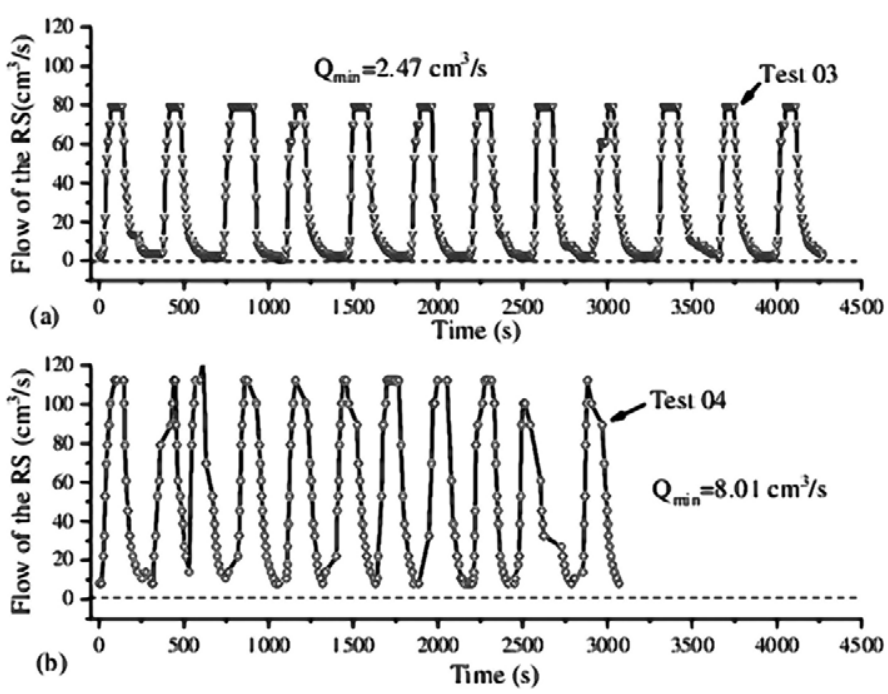

Figure 6 Relationship between flow of RKS and time in Tests 03 04: (a) flow of the RKS evolving regularly with time, the increase in replenishment induced a low limit flow of the RKS and (b) a large replenishment of the cave-reservoir caused irregular changes in flow of the RKS with time, and more cycles appeared in the same duration.

continuous infiltration and recharge from the top of the cave-reservoir, the second process of RKS functioning was formed and replayed.

The change in water level in the cave-reservoir with time can be expressed as:

$$
h_{1}(t)=\left\{\begin{array}{c}
\frac{Q_{0} t}{A_{1}}, 0<t<t_{c r} \\
\Delta h_{\text {max }}, t=t_{c r} \\
\frac{\left(Q-Q_{0}\right)^{t}}{A_{1}}, t_{c r}<t<T
\end{array} .\right.
$$

In Equation (9), $t_{c r}$ is the moment when the water level reaches the siphon critical point; $T$ is the cycle duration; $\Delta h_{\max }$ is the maximum value of the water level in the cave-reservoir, $\Delta h=h_{1}-h_{3}$. According to Equation (6) and Equation (9), when $t_{c r}<t<T$, the function $h_{1}(t)$ can be expressed as $h_{1}(t) A_{1}=A_{2} t \sqrt{2 h g_{1}(t)}-Q_{0} t$. Then, it can be simplified to

$$
t=\frac{A_{1} h_{1}(t)}{A_{2} \sqrt{2 g h_{1}(t)}-Q_{0}},
$$

which forces $h_{1}(t)$ to change from $\Delta h_{\max }$ to 0 after the siphon effect starts. The cycle duration $T$ is the sum of the time of water increasing and water decreasing.

$$
T=\frac{A_{1} \Delta h_{\max }}{Q_{0}}+\int_{\Delta h_{\max }}^{0} \frac{A_{1} h_{1}(t) d h_{1}(t)}{A_{2} \sqrt{2 g h_{1}(t)}-Q_{0}} .
$$

Through the definite integral of Equation (11), the cycle duration was derived

$$
T=A_{1} \Delta h_{\max }\left(\frac{1}{Q_{0}}-\frac{3 Q 0}{2 g A_{2}^{2}}\right)+\frac{A_{1}}{A_{2}}\left(\frac{\Delta h_{\max }^{1.5}}{3 \sqrt{g}}+\frac{6 Q_{0}^{2} \sqrt{2 g h_{\max }}-\ln \sqrt{2 g \Delta h_{\max }}}{2 A_{2}^{2} g}\right) .
$$

Equation (12) indicates that the cycle duration depends on $A_{1}, A_{2}, Q_{0}$ and $\Delta h_{\max }$.

\section{Dynamic Features of Rhythmic Karst Spring by Physical Model Tests}

A total of eight tests were carried out in this study. The results of these tests are presented in Table 3 . The tests can be grouped into two categories according to the flow of the RKSs: (1) rhythmic and flow uncut (in Test 3 and Test 4); (2) rhythmic but flow cut-off (the rest of the tests). The results of the tests also show that the evolving feature of the hydrograph changed with the variable volume of cave-reservoir and the replenishment into the cave-reservoir. These

Table 3. Values of variables from the data of the 8 tests. The volume of cave-reservoir is the same in Test 1 Test 5 and Test 7 , while Test 6 and Test 8 have the same volume of cave-reservoir.

\begin{tabular}{cccccc}
\hline $\begin{array}{c}\text { Test } \\
\text { Number }\end{array}$ & $\begin{array}{c}\text { Replenishment by } \\
\text { Infiltrating } Q_{\mathbf{0}}\left(\mathbf{c m}^{\mathbf{3}} \mathbf{s}^{-1}\right)\end{array}$ & $\begin{array}{c}\text { Volume of Cave- } \\
\text { Reservoir } V_{R}\left(\mathbf{c m}^{\mathbf{3}}\right)\end{array}$ & $\begin{array}{c}\text { Max. Flow of the RS } \\
\mathbf{Q}_{\mathbf{m a x}}\left(\mathbf{c m}^{\mathbf{3}} \mathbf{s}^{-1}\right)\end{array}$ & $\begin{array}{c}\text { Min. Flow of the RS } \\
Q_{\min }\left(\mathbf{c m}^{\mathbf{3}} \mathbf{s}^{-1}\right)\end{array}$ & $\begin{array}{c}\text { Average Cycle } \\
\text { Duration }(\mathbf{s})\end{array}$ \\
\hline 1 & 21.70 & 3973 & 56.72 & 0 & 340 \\
2 & 28.45 & 3973 & 69.67 & 0 & 399 \\
3 & 33.25 & 3973 & 79.2 & 2.47 & 361 \\
4 & 57.24 & 3973 & 124.93 & 8.01 & 273 \\
5 & 19.80 & 3973 & 52.75 & 0 & 325 \\
6 & 19.80 & 11917 & 52.75 & 0 & 644 \\
7 & 27.30 & 3973 & 65.49 & 0 & 339 \\
8 & 27.30 & 11917 & 66.11 & 0 & 608 \\
\hline
\end{tabular}

tests were conducted under different water replenishment volumes into the cave-reservoir from Test $01 \sim$ Test 04 , and Test 05, and Test 07. Test 05 and Test 06, Test 07 and Test 08 were considered as two general groups with the same infiltrating flow but different volumes of the cave-reservoir in each group (Table 3). Due to the similar conditions in the two groups, it is not necessary to present all of the hydrographs herein. 


\section{Rhythmic and Flow Cut-Off}

In Test 01, the replenishment into the cave-reservoir was $21.7 \mathrm{~cm}^{3} \mathrm{~s}^{-1}$. Water level rose up linearly in the cave-reservoir and the flow of the RKS $(Q)$ was equal to zero. The flow of the RKS was not equal to zero until the water overflowed to the bottom of the siphon position (Fig. 4, point 2), and then the flow of the RS increased with the continuous rise in water level. The siphon effect acted as soon as the water level in the cave-reservoir reached the highest point, with a maximum value of flow of the RKS. The maximum flow remained for some time and then decreased by the reducing siphon effect, because flow of the RKS was much higher than the recharging flow $\left(Q_{0}\right)$. Water level in the cave-reservoir dropped rapidly first and then slowly. The flow of the RKS attenuated first and slowed later. Moreover, it had a much slower decreasing duration and was equal to zero when the water level dropped to $h_{3}$ (Fig. 5a). Subsequently, the flow was cut-off. According to the hydrograph, 10 peaks were generated over the entire test time of 3450 seconds. The average cycle duration was $340 \mathrm{~s}$. The maximum and minimum flow values of the RKS were equal to $56.72 \mathrm{~cm}^{3} \mathrm{~s}^{-1}$ and 0 $\mathrm{cm}^{3} \mathrm{~s}^{-1}$, respectively. Moreover, the intermittent characteristic was obvious and the cycles were regular.

The replenishment of the cave-reservoir was $28.45 \mathrm{~cm}^{3} \mathrm{~s}^{-1}$ in Test 02 . It can be easily seen that the hydrograph shape was irregular, and each cycle had a variable duration; sometimes longer, sometimes shorter. The average cycle duration was equal to $399 \mathrm{~s}$, and the maximum and minimum flow values of the RS were equal to $69.67 \mathrm{~cm}^{3} \mathrm{~s}^{-1} \mathrm{and}^{0} \mathrm{~cm}^{3}$ $\mathrm{s}^{-1}$, respectively. However, 10 peaks were generated during the entire testing time of $3492 \mathrm{~s}$. Although the siphon effect was the same as in Test 01, the peak values could not maintain a certain period in some of the cycles. Rapid increase and decrease were observed (Fig. 5b) compared with Test 01 and Test 02 . We found that the larger the replenishment volume, the greater the maximum flow value of the RKS. The minimum value of flow of the RKS was equal to zero due to the sufficient volume of replenishment received by the cave-reservoir, also because the flow of the RKS was greater and the replenishment was relatively smaller. When the water level in the cave-reservoir dropped to the connection of karst pipe and the cave-reservoir, air bubbles entered the pipe and attenuated the siphon effect from the water surface in the cave-reservoir. Flow of the RKS was eventually cut-off in a cycle duration when the flow rate is zero.

\section{Rhythmic and Flow Uncut}

The rhythmic phenomenon still existed in Test 03. The replenishment was equal to $33.25 \mathrm{~cm}^{3} \mathrm{~s}^{-1}$. The maximum flow of the RKS was equal to $79.2 \mathrm{~cm}^{3} \mathrm{~s}^{-1}$, while the minimum flow of the RKS was equal to $2.47 \mathrm{~cm}^{3} \mathrm{~s}^{-1}$ for all the tests. The cycles were regular and the cycle duration was $361 \mathrm{~s}$. There were 12 peaks generated during the entire test period. The peak flow of the RKS was maintained in some of the cycles. However, the minimum flow of the RS lasted a longer time than the maximum ones in each cycle (Fig. 6a). In contrast to Test 01 and Test 02, the minimum flow of the RS was greater than zero and was a constant value in every cycle in Test 03, which indicates that a rhythmic stream was always in the karst pipe throughout the test. Similar to the earlier tests, the greater the replenishment, the greater the peak flow of the RKS. The replenishment was large enough and the volume of the cave-reservoir was constant, so that the flow of RKS was never cut. Once the water level in the cave-reservoir dropped to the connector of joint position (Fig. 4, point 3), only a few air bubbles went into the karst pipe. The sufficient recharge induced the water level in cave-reservoir to rise again and generated the next siphon effect under the condition of a little stream in the karst pipe.

The replenishment into the cave-reservoir was equal to $57.24 \mathrm{~cm}^{3} \mathrm{~s}^{-1}$. The maximum and minimum flow values of the RKS were $124.93 \mathrm{~cm}^{3} \mathrm{~s}^{-1}$ and $8.01 \mathrm{~cm}^{3} \mathrm{~s}^{-1}$, respectively, which clearly shows that the maximum flow of the RKS increased with the increase in replenishment. According to the hydrograph of Test 04 (Fig. 6b), flow of the RKS changed rapidly. It increased fast and reached the peak value in a short time, and then decreased soon, and then increased rapidly again for the next cycle. The cycles were not stable, some of them presented a short cycle while other cycles showed a regularly changing process. The average cycle duration was $273 \mathrm{~s}$. There were 11 cycles in this test, and the total consumed time was equal to 3068 seconds. Similar to Test 03, there was limited volume of the cave-reservoir but abundant water recharge flowed into the cave-reservoir, which caused the flow of the RKS at the trough periods.

\section{Variable Volume of Cave-Reservoir}

Test 05 and Test 06 were carried out to ascertain the relationship between the cycle duration and the volume of the cave-reservoir. The volumes of Test 05 and Test 06 were $3973 \mathrm{~cm}^{3}$ and $11917 \mathrm{~cm}^{3}$, respectively. The replenishment was a constant $19.8 \mathrm{~cm}^{3} \mathrm{~s}^{-1}$ in the two tests.

In Test 05, the hydrograph shape was similar to the aforementioned tests such as Test 01 and Test 03 . The maximum flow and the minimum flow of the RKS were equal to $52.75 \mathrm{~cm}^{3} / \mathrm{s}$ and $0 \mathrm{~cm}^{3} \mathrm{~s}^{-1}$, respectively. Therefore, it can also be regarded as a rhythmic and flow cut-off case, where the regular cycles and the peaks showed the same appearance (Fig. 7a). Its average cycle duration was 325 seconds. In contrast to Test 05 , the only difference in Test 06 was the volume of the cave-reservoir. The cycle duration was 644 seconds, which was quite different from the cycle duration in Test 05 (Fig. 7b). However, the maximum flow and the minimum flow of the RKS were the same. This result indicated that the scale of the reservoir formed by the dissolution of soluble rock in karst terrain has an important effect on the cycle duration. 


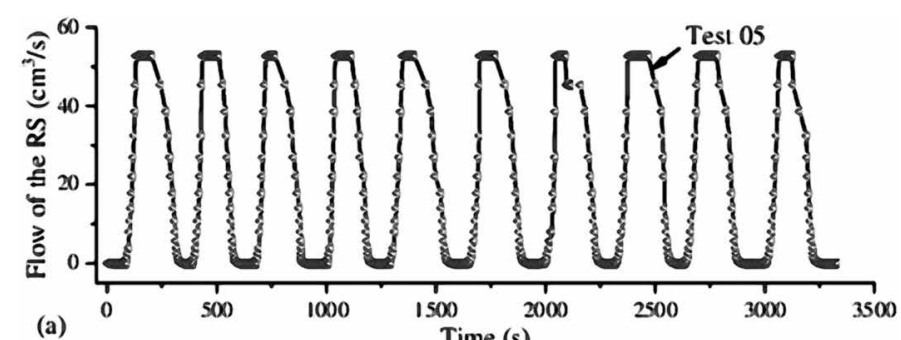

(a)

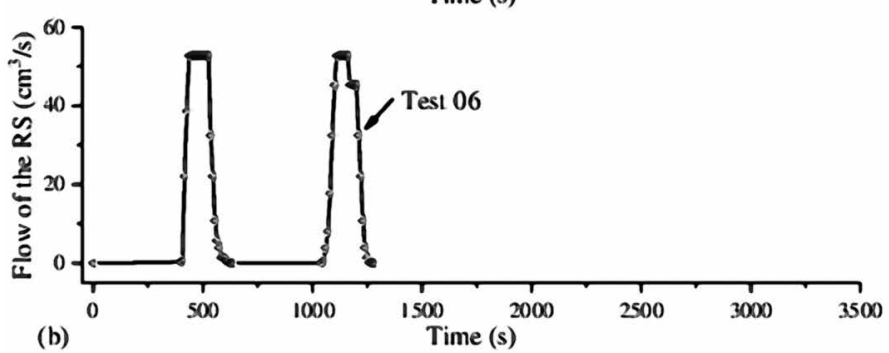

Figure 7 Relationship between flow of RKS and time in Test 05 and Test 06: (a) the volume of cave-reservoir was one-third of Test 06 , flow of the RKS changed regularly with time, 10 cycles in the whole test and the average cycle duration was 325 seconds and (b) the volume of cave-reservoir was increased, three times larger than Test 05. The same replenishment and different volumes of cave-reservoir caused a variable cycle duration.
Replenishment from the top or the lateral karst pipe into the cave-reservoir depends on the hydrogeological and environmental conditions in the karst terrains. Stable replenishment provides a siphon effect for a unique karst system. The increased replenishment can provide an increase in flow of the RKS with variable cycle duration under different replenishment volumes. Compared with Test 05 and Test 06 , the cycle duration of Test 07 and Test 08 increased with the increase in volume of the cave-reservoir under constant replenishment (Fig. 8a). According to the results of Tests $01 \sim 08$ (Test 05 was the same as Test 06, Test 07 was the same as Test 08), the maximum flow of the RKS and the replenishment showed linear correlation with a quadratic value of 0.995 (Fig. 8b). However, the minimum flow of the RKS changed in a different way. The minor replenishment in cave-reservoir can induce a siphon effect but the minimum flow was equal to zero periodically. When the replenishment was large enough, the minimum flow was no longer equal to zero, but it was periodic and changed synergistically with the maximum flow (Fig. 8c), indicating that there must exist a critical replenishment value that can be used to distinguish the categories of RKS. The critical replenishment was around $30.85 \mathrm{~cm}^{3} / \mathrm{s}$ by linear interpolation calculation. Additionally, the average cycle duration increased from Test $01 \sim 02$, and presented an increasing trend. In contrast, the average cycle duration decreased from Test $02 \sim 04$. It can be inferred that the large enough replenishment caused a peak flow of the RKS, and little time was needed to induce the next cycle. The reason for the increasing average cycle duration can be considered as the combined influence of the constant volume of the
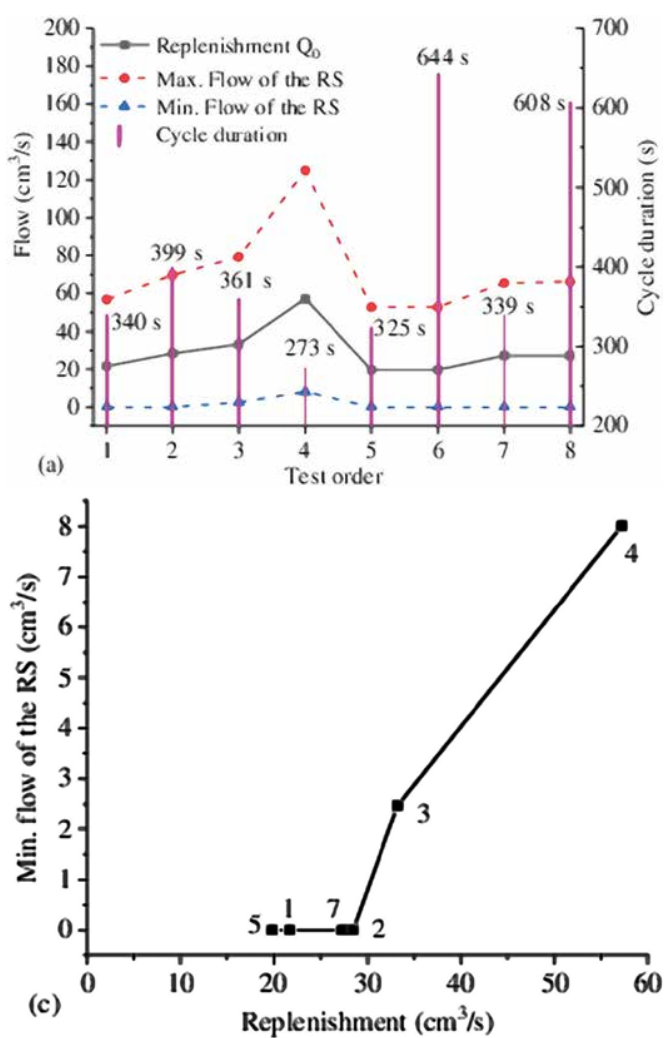
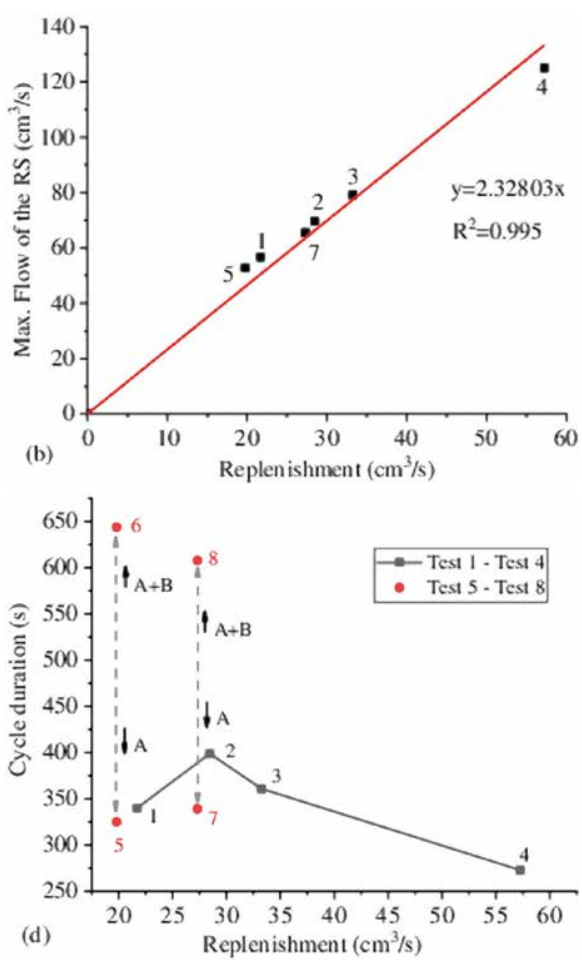

Figure 8 Relationship among the variables: (a) characterization points of the maximum flow of the RKS, minimum flow of the RKS, cycle duration and the replenishment in the experiments; (b) the linear increase between the maximum flow of the RKS and the replenishment; (c) relationship between the min. flow of the RKS and the replenishment, Tests $01 \sim 08$; and (d) relationship between cycle duration and replenishment in Tests $01 \sim 08$. cave-reservoir, the replenishment, and the maximum flow of the RKS.

The cycle duration increased first, reached a peak value and then decreased with the increase in water replenishment in a constant volume of cave-reservoir (from Tests 05, 01, 07, 02, 03, and 04 one by one, Fig. 8d). Furthermore, for the same replenishment but different volumes of the cave-reservoir, the larger the volume, the longer the obtained duration. The range of cycle duration followed the bulk of cave-reservoir size from $A$ to $A+B$, and the cycle duration increased to the top or decreased to the bottom.

\section{DISCUSSION}

RKS in karst terrains are always related to the siphon effect. The geological process analysis methodology was used to understand the characteristic evolution of this kind of spring, because it is necessary to identify the geological and hydrogeological conditions in the area where rhythmic springs are found. Mathematical 
equations were employed to provide solutions for the parameters (e.g., the velocity of the RKS at the outlet, negative pressure at the siphon water level, replenishment for the cave-reservoir, the max. flow and the min. flow of the RKS, etc.). Multiple tests carried out with the physical model that simulates the rhythmic spring functioning in a karst system of soluble rocks including the real-time monitoring of the replenishment of the cave-reservoir, the flow of the RKS, and the cyclic duration. These data illustrated that the change in water replenishment for the cave-reservoir has a crucial impact on the functioning of RKS, including the correlation of the parameters. The difference in fissures, pipes, cavities, and the hydrology also induced variable modes of RKS.

\section{The Calculation of Characteristic Parameters}

Water flow velocity at the outlet of the RKS, flow of the RKS, negative pressure at the siphon critical point, and the cycle duration are the main characteristic parameters for describing the process of RKS quantitatively. According to the hydraulic theories, the water flow velocity at the outlet depends on the vertical difference between the water level in cave-reservoir and the outlet. According to Equation (7), the velocity acceleration increased first and decreased later. The higher the water level in the cave-reservoir, the greater the flow velocity at the outlet. The energy loss was neglected in the derivation, which may have an impact on the velocity calculation. In fact, water flow from the cave-reservoir to the outlet passes through the karst pipe, with an inner surface that is irregular and coarse. Hence, the velocity decreased all the time from the connection joint to the outlet. Due to the constant cross-sectional area of the outlet, the water flow velocity at the outlet is proportional to the flow of the RKS.

Negative pressure at the siphon critical point is the main dynamic force for the functioning of RKS. The negative pressure is up to the vertical difference of the siphon critical point to the outlet. It is a fixed value which provides the power directly for the RKS. It can be affected by air bubbles going through the karst pipe and disconnect the stream.

The cycle duration of the RKS can be calculated by Equation (15). Its values depend on the area of the bottom surface $A_{1}$, the cross-sectional area of the karst pipe $A_{2}$, the replenishment of the cave-reservoir $Q_{0}$, and the vertical difference between $h_{1}$ and $h_{1}\left(\Delta h_{\text {max }}\right)$. The replenishment of the cave-reservoir source consists of infiltration from precipitation, the lateral inflow from the karst pipe, and from cracks and fissures. The replenishment is stable on some days, and the volume of the cave-reservoir and the structure of karst pipe system remain almost constant. The cycle duration always remains relatively invariable.

\section{Replenishment and Flow of the RKS and Cycle Duration}

Flow of the RKS changes with the replenishment of cave-reservoir. Maximum and minimum flow of the RKS can be identified in the curves of relationship between flow and time by physical laboratory experiments. The value of replenishment of the cave-reservoir should be within a certain range. For instance, when the value of replenishment is less than the lower limit, all the replenished water outflows to the outlet through the karst pipe, and the water table in the cave-reservoir is stable all the time. Once the replenishment exceeds the upper limit, the spring appears as a normal spring commonly found in nature. The range of replenishment is a necessary condition for the siphon effect of the RKS. Maximum flow of the RKS increases linearly with the replenishment, due to the fixed volume of the cave-reservoir and the uniform karst pipe system. In contrast, the minimum flow of the RKS equals zero. At lower replenishment of the cave-reservoir, the siphon effect occurs. The minimum flow of the RKS exists until there is a large enough replenishment of the cave-reservoir. The presentation of minimum flow of the RKS indicates the distinction between rhythmic flow cut-off and rhythmic flow uncut.

The cycle duration increases with the increase in replenishment at a lower value. The cycle duration decreases when the minimum flow of the RKS is not equal to zero. The limit volume of the cave-reservoir and the increasing discharge from the outlet of the spring are observed. The cycle duration is extended when the volume of the cave-reservoir is increased.

\section{Different Shaped Cave-Reservoirs and Hydrographs}

As discussed, the shapes of the cave-reservoirs are different. A kidney-shaped reservoir was assumed in the physical model and a vertical reservoir was assumed in the analytical model. The hydrographs of the RKS depend on changes in flow over time. Flow of the RKS is related to the capability of the siphon effect and the rate of decrease in water level in the reservoir. When the siphon effects of the kidney-shaped reservoir system and the vertical reservoir system are the same, assuming the replenishment are the same, the kidney-shaped reservoir is irregular from the higher water level to the lower position vertically, which induces a varying rate of decrease in water level all the time. Consequently, the hydrograph will have the following features: (1) less time is needed from the initial water level to the siphon water level, and less time is needed from zero to the peak value for the flow. There is shorter duration of the peak value, which decreases faster to the end of the cycle; (2) close to the end of the cycle, at the bottom of the hydrograph, the flow decreases step by step and a smoother curve can be obtained. For the vertical reservoir system, the hydrograph appears smoother both in the ascending phase and the descending phase of the flow, and the peak flow is maintained longer. 


\section{CONCLUSIONS}

A physical laboratory model was constructed for the RKS that occurs in the karst terrains. Both the mathematical analysis and the physical laboratory tests provided useful quantitative information on the rhythmic springs process and the hydrology parameters. The mathematical analysis provided some crucial parameters including the water flow velocity at the outlet of the RKS, flow of the RKS, negative pressure at the siphon point, and the cycle duration by formula derivation. Tests were performed with a laboratory-scale physical model to simulate the intermittent phenomenon of springs in the karst terrains. The results of the experiments demonstrate that the existence of a siphon effect is key for the functioning of RKS. Moreover, the following relationships between the replenishment and flow of the RKS, and the cycle duration were revealed:

1. The replenishment should be a ranged value. The lower limit and the upper limit are the necessary conditions for a rhythmic spring. The maximum flow of the RKS was proportional to the replenishment of the cave-reservoir, while the minimum flow of the RKS required a large enough replenishment of the cave-reservoir. Less replenishment caused a rhythmic phenomenon without a minimum flow of the RKS. There must exist a critical value of replenishment for the categories of RKS.

2. Cycle duration changed with the change in the replenishment volume. It increased under lower replenishment but decreased with increased replenishment. The cycle duration attenuated once minimum flow of the RKS was no longer equal to zero. The cycle duration was extended when the volume of the cave-reservoir expanded. The hydrographs were different between a kidney-shaped reservoir system and a vertical reservoir system.

\section{ACKNOWLEDGMENTS}

We thank all of our colleagues with whom we have discussed rhythmic springs in the field and lab over the past several years and also the associate editor and two anonymous reviewers for their comments. This work was initiated with support from the National Natural Science Foundation of China NSFC Grant (No. 41502244) and was continued with support from Fundamental Research Fund of SKLGP (No. SKLGP2018Z023). These financial supporters are gratefully acknowledged.

\section{REFERENCES}

Atkinson, T.C., 1986, Soluble rock terrains: in Fookes, P.G., and Vaughyn, P.R eds., A Handbook of Engineering Geomorphology, Chapman \& Hall, p. 241-257.

Atwell, J., 1732, Conjectures upon the nature of intermitting and reciprocating springs: Philosophical Transactions, v. 37, p. $301-316$.

Bögli, A., 1980, Karst Hydrology and Physical Speleology. Springer Verlag, Berlin, v. xii, 284 p. https://doi.org/10.1007/978-3-642-67669-7.

Bonacci, O, 1987, Karst Hydrology. Springer Verlag, Berlin. https://doi.org/10.1007/978-3-642-83165-2

Bonacci, O., and Bojanic D., 1991, Rhythmic karst springs: Hydrological Sciences Journal, v. 36, no. 1, p. 35-47. https://doi. org/10.1080/02626669109492483.

Casteleyn, J.A., Van Groen, P. and Kolkrnan, P.A., 1977, Air entrainment in siphons: Results of tests in two scale models and an attempt at extrapolation: Delft Hydraulics Laboratory Publ. no. 187.

Cvijić, J., 1896, Izvori, tresave i vodopadi u istočnoj Srbiji, Glasnik srpske kraljevske akademije, sveska LI, Beograd.

Gavrilović, D., 1967, Intermitentni izvori u Jugoslaviji (Rhythmic springs in Yugoslavia). Glasnik Srpskog Geografskog Drustva XLVII (1), p. 13-36Gavrilović, D., and Gavrilović, L. J., 1985, Intermitentni izvor Zaslapnica (Rhythmic spring Zaslapnica): Glasnik Srpskog Geografskog Drustva LXV (2), p. 35-41lgračev N., 2014, Comparative analysis of the flow activity of the Homoljska potajnica intermittent spring: Journal of the Geographic Institute "Jovan Cvijic" SABA, v. 64, no. 1, p. 1-12. DOI: 10.2298/IJGI1401001IKatzer, F., 1909, Karst und Karsthydrographie: Zur Kde, Balkanhaldbinsel 8, Sarajevo.

Lazarević, R., 1990, Kučevska potajnica, Zavod za novinsko - izdavačku i propagandnu delatnost, JŽ, Beograd.

Kolda, A., Petrić, I., Mucko, M., Gottstein, S., Žutinić, P., Goreta, G., Ternjen, I., Rubinić, J., Radišić, M., and Gligora Udovič, M., 2019, How environment selects: Resilience and survival of microbial mat community within intermittent karst spring Krčić (Croatia): Ecohydrology.12: e2063. https://doi.org/10.1002/ eco.2063

Lazarević, R., 2000, Geomorfologija, Prirodno - matematički fakultet, odsek za geografiju, Banja Luk.a

Marković, J., 1963, Homoljska potajnica, Glasnik srpskog geografskog društva, sveska XLIII, broj 2, Beograd.

Mather, J.D., 2013, The history and hydrogeology of Laywell, a celebrated ebb and flow spring at Brixham: Devon: Rep. Transactions of the Devon. Association for the Advancement of Science, v. 145, p. 133-154.

Mirković, S., Miljković, L., 2006, Turistička valorizacija i zaštita Homolsjke potajnice: Kongres srpskih geografa, Zbornik radova, knjiga 1, str. 801806, Soko Banja Cvijić J. (1896). Izvori, tresave i vodopadi u istočnoj Srbiji, Glasnik srpske kraljevske akademije, sveska LI, Beograd.

Oliver, W., 1693, An extract of a letter from Dr William Oliver, communicated by Walter Moyle, Esq: Philosophical Transactions, v. 17, p. 908-909.

Oraseanu, I., 2010, Calugari ebb and flow spring: in Oraseanu, I., and lurkiewicz, A. eds., Karst Hydrogeology of Romania (Belvedere, Oradea, Romania), p. 262-274.

Petrović, J., 1981, Udvojena potajnica Promuklica (Double karst rhythmic spring Promuklica): Glasnik Srpskog Geografskog DruStva, v. LXI, no.1, p. 333=343.

Stephens, G., 1964, Rhythmic springs: Cave Research Group of Great Britain, Transactions: Ledbury (Herefordshire) Tomo, v. 7, no. 1, p. 3-9. 